\title{
Restless Leg Syndrome in children: an undiagnosed entity
}

\author{
Manvir Bhatia, Nandeeshwara S.B
}

Sir Ganga Ram Hospital, Rajinder Nagar, New Delhi

Indian J Sleep Med 2007; 2.2, 71-72

$\mathrm{T}$ The restless leg syndrome (RLS) is characterised by an urge to move the legs usually associated with unpleasant leg sensation. Typically symptoms worsen at rest and they are atleast temporarily relieved by activity. Usually these symptoms are worse or begin in the evening or at night. (1)

There are many subtle variations of this disorder. To complicate the matter, the diagnosis is purely clinical and thus depends on accurate history and even less is known about it in children. Consequently, RLS in children is underdiagnosed.

Here we present a case of RLS in a child whose diagnosis was delayed for more than one year due to which there was a significant effect on patient's quality of life. This is the first case of RLS in children reported in India to the best of our knowledge.

A girl aged 15 years presented with c/o increased sleep episodes since September 2006. The teachers reported that she would sleep during the morning prayer and during the class hours. Often they found it difficult to wake her up and had to call her parents. There was a drastic decrease in scholastic performance. She was shown to many local doctors with no response. Later she was brought to dept. of Sleep Medicine, SGRH, New Delhi in April 2007. On detailed history it was found that her sleep rhythm was completely disrupted. She had delayed sleep onset by about 5-6 hrs. Though

\footnotetext{
Address for Correspondence

Dr. Manvir Bhatia

Chairperson Sleep Medicine \&

Senior Consultant Neurology

Sir Ganga Ram Hospital, New Delhi, India

Tel No: 01142251728 , Fax No: 01125861002

Email address: manvirbhatial@yahoo.com

Website: www.sleepwellindia.com
}

she lay at 9 p.m. would sleep at 2-3 a.m. On direct questioning she complained of feeling restlessness in her legs with an urge to move them at sleep onset. She used to keep tossing and turning in the bed which slightly relieved her symptoms. Her daytime performance was severely reduced as she felt tired throughout the day with increased sleepiness, had difficulty in concentrating in class. She responded positively for all the symptoms of RLS (1). There was no family history of RLS. Her serum ferritin and Vit.B12 were $4 \mathrm{ng} / \mathrm{ml}$ and $244 \mathrm{pmol} / \mathrm{lt}$, respectively. She was treated with methyl cobalamin, Iron supplements and pramipexole. On follow up, 2 months later she has had no further episodes of increased sleep and there is a marked improvement in her school performance.

\section{Discussion}

RLS is one of the commonest neurological disorder with a prevalence of $5-10 \%$ in general population (2) and around $5.6 \%$ in children (3). For a diagnosis of RLS in children, the child must meet all 4 essential adult criteria (1) and describe the sensations in her own words. If the child is unable to describe, then atleast 2 of the following must be present:

(a) Sleep disturbance not typical for the age

(b) a biological parent or sibling with a definitive RLS

(c) PSG documented periodic leg movements (PLMs) index $>5$ (4). These were all present in our patient.

Central dopaminergic systems are involved in the pathogenesis of RLS based on the fact that dopaminergic medications improve RLS symptoms (5). RLS can occur as a primary disorder, with no apparent cause other than a genetic predisposition or as a secondary condition most

Indian Journal of Sleep Medicine (IJSM), Vol. 2, No. 2, 2007 
commonly related to iron deficiency (6), which is integral for biosynthesis of dopamine. In our patient, she had severe Fe deficiency, which probably caused the RLS. Treatment of RLS in children is controversial with no specific recommendations in the standards of practise committee of American academy of Sleep Medicine (7). The best initial form of treatment is to treat the secondary causes like iron deficiency. Certain medications like dopamine agonists (ropinirole, pramipexole) have been tried with good results (8). Good sleep hygiene can be helpful in children.

The diagnosis and treatment of RLS in children is often challenging. Furthermore many conditions like growing pains, motor tics, ADHD and leg cramps can mimic symptoms of RLS. If not treated, RLS in children can result in serious behavioral consequences including impaired daytime functioning and poor social interactions. Thus $\mathrm{i}$ there is a need for its prompt diagnosis and appropriate treatment.

Our patient had significant relief with treatment. Thus this case is presented as it highlights the importance of a correct diagnosis thereby improving the quality of life.

\section{References}

1. Allen RP, Picchietti D, Hening WA, Trenkwalder C, Walters AS, Montplaisi J. Restless leg syndrome diagnosis and epidimiology workshop at the National Institute of Health International Restless legs syndrome study group. Sleep Med 2003;4(2):101-19.

2. Allen RP, Early CJ. Restless legs syndrome: a review of clinical and pathophysiological aspects. Clinical Neurophysiology 2001;18:128-147.

3. Kotagal S, Silber MH. Childhood-onset restless legs syndrome. Ann Neurol.2004;803-807.

4. Murali Maheswaran, Clete A. Kushida. Restless Legs Syndrome in Children. Med Gen Med. 2006; 8(2): 79.

5. Desautels A, Turecki G,Montplaisir J, et al. Restless leg syndrome; confirmation of linkage to chromosome $12 q$,genetic heterogeinity and evidence of complexity. Arch Neurol.2005;62:591-596.

6. Earley CJ, Allen RP, Beard JL, Connor JR. Insight into the pathophysiology of RLS. Journ Neurosciences $2000 ; 62(5): 623-8$

7. Chesson AL Jr, Wise M, Davila D, et al. Practise parameters for the treatment of restless leg syndrome and periodic limb movement disorder. An American Academy of sleep medicine report. Standards Committee of the American Academy of Sleep Medicine. Sleep.1999;22:961-968.

8. Walters AS, Mendelbaum DE, Lewin DS, Kugler S, England SJ, Miller M. The dopaminergic studygroup. Dopaminergic therapy in children with restless legs/periodic limb movements in sleep and ADHD. Paediatr Neurol.2000;22:182-186. 